\title{
EL MATRIMONIO, EL CONCILIO DE TRENTO E HISPANOAMÉRICA
}

POR

\author{
MÓNICA GHIRARDI
}

Universidad Nacional de Córdoba, Argentina

ANTONIO IRIGOYEN LÓPEZ

Universidad de Murcia, España

\begin{abstract}
Este trabajo pretende indagar sobre la normativa tridentina acerca del matrimonio y la problemática en torno a la institución matrimonial en la América hispana. Se persigue sopesar el grado de observancia y cumplimiento de las disposiciones tridentinas y reflexionar sobre el éxito, o el fracaso, del programa conformador de la organización social en América emprendido por la Monarquía hispánica y la Iglesia católica, en el cual el matrimonio era una pieza de significativa importancia. Fuentes de archivo inéditas consistentes en Causas matrimoniales de separación, nulidad e incumplimiento de promesa matrimonial correspondientes al tribunal diocesano de Córdoba, en la actual Argentina, en el periodo 1688-1850, proporcionan elementos de reflexión y análisis.

Palabras clave: Concilio de Trento, matrimonio, divorcio, familia, historia social, Córdoba-Argentina.
\end{abstract}

\section{INTRODUCCIÓN}

Afirma Jean Louis Flandrin que los matrimonios de otrora resultan incomprensibles si se los encara como asunto puramente privado y que en las sociedades monárquicas la institución familiar tenía características de institución pública y las relaciones de parentesco servían como modelo a relaciones sociales y políticas $^{1}$. Desde los siglos bajomedievales, primero con las normas impuestas

1 Flandrin, 1979: 7-8. 
por la Iglesia y más tarde con la intervención del Estado en esta materia, la cuestión matrimonial, desde el espacio de la intimidad, fue introduciéndose en el ámbito de lo público y así se mantendría, tironeada entre ambos aspectos ${ }^{2}$. Con todo, puede decirse que, desde entonces y hasta hoy, la institución matrimonial ha sido sinónimo de conflicto: algunos encuentros y muchos desencuentros, a pesar de los intentos del Concilio de Trento de clarificar la situación ${ }^{3}$.

Esta inestabilidad fue la que se trasladó a la América colonial tras la conquista española. Este trabajo pretende, en primera instancia, indagar sobre la normativa tridentina sobre el matrimonio. Lo cual implica que haya que prestar atención tanto a sus fundamentos medievales, muchos de los cuales permanecerán durante varios siglos, como a los problemas que rodearán la institución matrimonial en la América hispana. Un estudio de caso realizado a través de expedientes incoados en el tribunal diocesano de Córdoba del Tucumán del período 1688-1850 proporcionará elementos de reflexión y análisis. Todo lo anterior persigue analizar el grado de observancia y cumplimiento de las disposiciones tridentinas y reflexionar sobre el éxito, o el fracaso, del programa conformador de la organización social en América emprendido por la Monarquía hispánica y la Iglesia católica, en el cual el matrimonio era una pieza más: ¿la fundamental?

\section{LA FAMILIA Y EL MATRIMONIO PARA LA IGLESIA}

Durante la Edad Media, el matrimonio fue competencia exclusiva de la Iglesia; ningún poder seglar le discutió su autoridad ni su doble monopolio, jurisdiccional y legislativo ${ }^{4}$. Por consiguiente, las polémicas tuvieron lugar en su seno. Las principales diferencias teóricas habían surgido entre los canonistas de la escuela de Bolonia y los teólogos de la escuela de París, sin olvidar que aun dentro de cada uno de estos grupos tampoco el discurso era único. El punto de fricción se encontraba en el tema de la significación y la formación del vínculo. Los teólogos, inspirados en la tradición jurídica romana, sostenían que era por el consensus, el consentimiento de los esposos, cuando se realizaba el sacramento ${ }^{5}$. En cambio, para los canonistas de Bolonia mediante la co-

2 Ariès, 1987b: 189-228, en especial, 214.

3 Candau Chacón, 2006: 175-202. En cualquier caso, son numerosos los trabajos que han tratado sobre esta temática en la América colonial; sólo a título de ejemplo pueden mencionarse: Lavrin, 1991. Ghirardi, 2004; 2005. Ortega Noriega, 2000.

4 Gaudemet, 1993: 165-171. Brundage, 2000.

5 Pedro Lombardo y, luego, Huguccio sostuvieron que el consentimiento era principio ori- 
pula, la consumación carnal, se completaba la doble significación del matrimonio: la del alma fiel con Dios, y la de Cristo con la Iglesia ${ }^{6}$.

Estas diferencias proporcionaron todo un vocabulario que habría de triunfar en los años y siglos venideros y que tenía que ver con las distintas etapas por las que atravesaba el vínculo matrimonial ${ }^{7}$. De este modo, cabe hablar de matrimonium initiatum para los esponsales, son las «palabras de futuro», mero intercambio de consentimientos; matrimonium ratum para las «palabras de presente», momento en que quedaba creado el vínculo; y matrimonium consummatum para la unión sexual, cuando pasaba a ser indisoluble ${ }^{8}$. Se fusionaban así las teorías consensualistas y copulativas9.

Aunque ya en la época del apogeo escolástico quedó fijado que el matrimonio era un sacramento ${ }^{10}$, habrá que esperar al Concilio de Florencia de 1438, para encontrar una declaración explícita del Magisterio sobre el sacramento del matrimonio ${ }^{11}$.

Pese a todo, seguían existiendo notables desavenencias: los elementos constitutivos del sacramento del matrimonio (materia, forma y ministros); la concesión de la gracia; la teoría de los impedimentos; la indisolubilidad del matrimonio; y, sobre todo, las controversias sobre la libertad de los contrayentes y el consentimiento familiar con el grave problema añadido de los matrimonios clandestinos, convertidos ya en una auténtica plaga social ${ }^{12}$, por lo que empezaron a ser condenados de forma reiterada en los sínodos y concilios provincia$\operatorname{les}^{13}$. Fue tal la inseguridad jurídica que originó el extenderse los matrimonios clandestinos que la cultura jurídica europea comenzó a subrayar el aspecto «público» del matrimonio ${ }^{14}$. Como bien dice Kamen, antes del siglo XVI la institución del matrimonio parecía encontrarse en un estado de gran confusión ${ }^{15}$.

ginario y causa eficiente del matrimonio: Rincón, 1971: 182-189 y 237-243. Gaudemet, 1993: 204.

6 Rincón, 1971: 219.

7 Anticipado por Graciano y fijado por Enrique de Susa, el Hostiense.

8 Gaudemet, 1993: 207.

9 Rincón, 1971: 386-390. El consentimiento es un elemento necesario y suficiente para constituir esencialmente un matrimonio. La cópula carnal no añade nada sustancial al ser matrimonial. No obstante, sus múltiples implicaciones jurídicas hacen de ella un elemento insoslayable, además de añadir una mayor perfección al matrimonio pues significa la unión por la carne de Cristo con la Iglesia.

10 Gaudemet, 1993: 205-221. Rincón, 1971: 123-251 y 279-369. Tejero, 1971: 20 y 100.

11 Tejero, 1971: 101-103. Jedin, 1975: III/221.

12 Gaudemet, 1993: 221-272. Carreras, 2002: 83.

13 Aznar Gil, 25 (Madrid, 2003): 189-214. Tejero, 1971: 99.

14 Carreras, 2002: 81.

15 Kamen, 1998: 262. 
Ante la ofensiva de las iglesias reformadas que negaron el carácter sacramental del matrimonio, la respuesta católica fue diversa y, en ocasiones, difur $\mathrm{sa}^{16}$. Al inicio del Concilio de Trento, la fundamentación teológica era débil y adolecía de unidad, lo que se traducía en una gran inseguridad acerca de la teología sacramental; por todas estas razones, no puede sorprender el hecho de que la cuestión del sacramento del matrimonio fuera una de las más debatidas en el Concilio, aunque al final hubiera unanimidad prácticamente general ${ }^{17}$. El matrimonio es sacramento de la nueva alianza no por la nueva institución de Cristo, sino por introducción del matrimonio unitario, que representa la unión de Cristo y de la Iglesia y posee una promisión de gracia; la sacramentalidad es la razón última de su indisolubilidad ${ }^{18}$.

A pesar de lo cual, no acabaron aquí las controversias. El centro de la discusión giraba en torno a los matrimonios clandestinos ${ }^{19}$, puesto que del tratamiento que de ellos hiciera el Concilio se desprendería la labor reformadora en torno al matrimonio. Cuestión que habría de girar sobre tres ejes: la publicidad, la celebración y el consentimiento paterno, causa de numerosos conflictos familiare ${ }^{20}$. Sin embargo, la solución no era sencilla pues invadía a los padres conciliares un doble temor: innovar y reformar demasiado, puesto que se podría cuestionar la Tradición y, lo más peligroso, acercarse a las posturas de los protestantes $^{21}$. La solución habría de venir del célebre decreto de reforma, que no dogmático, Tametsi.

En efecto, lo que el Concilio aprobó fue el reconocimiento expreso del poder de la Iglesia de establecer y declarar impedimentos matrimoniales, así como la jurisdicción eclesiástica en materia matrimonial ${ }^{22}$. El decreto Tametsi debe contemplarse como una solución de compromiso ante el grave problema de los matrimonios clandestinos - declarados nulos a partir del Concilio de Trento a diferencia de los celebrados sin el consentimiento de los padres, prohibidos pero tolerados y con validez canónica - y el remedio de dar la mayor publicidad posible a los enlaces. Así, siguiendo lo dispuesto en el Concilio

16 La mejor muestra sería el pensamiento de Erasmo de Rotterdam quien, sin negar la sacramentalidad, exponía varias objecciones: Tejero, 1971: 172-182; Jedin, 1975: 220. Watt, 2002: 206-207.

17 Jedin, 1975: 217-245.

18 Jedin, 1981: 152-153.

19 Ya se trate de los efectuados sin el consentimiento paterno de los cónyuges como de aquellos que se realizaban sin testigos y sin el consentimiento de la Iglesia: Jedin, 1975: 225.

20 Jedin, 1981: 158-168.

21 Gaudemet, 1993: 331-333. Carreras, 2002: 87. Watt, 2002: 226-227.

22 No hay que olvidar que la aprobación del Decreto se realizó con 47 votos en contra: Jedin, 1981: 242 . 
de Letrán (1215), impulsó la publicación de las amonestaciones en la propia parroquia durante tres domingos consecutivos ${ }^{23}$. Además, estableció la forma sustancial del matrimonio, declarando nulos los matrimonios celebrados sin la presencia del párroco (o de un sacerdote delegado) y de dos o tres testigos ${ }^{24}$.

Pero donde más se puede contemplar el delicado equilibrio a que se llegó fue en la cuestión del consentimiento paterno: declaraba la validez de los matrimonios clandestinos (realizados sin permiso paterno), aunque manifestaba la repulsa y prohibición que para con ellos siempre había tenido la Iglesia ${ }^{25}$. Con todas estas medidas, según Dedieu, se pretendió hacer del matrimonio algo religioso, al tiempo que se perseguía un cierto control sobre la sociedad y las familias ${ }^{26}$. En este punto, coincidieron protestantes y católicos: el control del matrimonio y la sexualidad reflejaban un deseo general, de corte patriarcal y paternalista, de promover el orden y la disciplina ${ }^{27}$. Al final, como señala Joan Carreras, lo que hizo el Concilio de Trento fue inventar «el matrimonio legal» ${ }^{28}$ : una forma de celebración que, pese a algunas dificultades iniciales de aplicación, en la práctica ha llegado hasta nuestros días ${ }^{29}$.

Por lo tanto, el Concilio de Trento fijó un modelo matrimonial que impuso a la sociedad en las regiones católicas. Si el matrimonio era un sacramento, la autoridad de la Iglesia y su competencia sobre el vínculo eran incuestionables. Así, la Iglesia logró mantener su hegemonía jurisdiccional sobre el matrimonio. La mayoría de los cánones tridentinos insistían en su competencia para dirimir todas las cuestiones; el último canon resume a la perfección el estado de cosas al que se había llegado: «Si alguno dijere, que las causas matrimoniales no pertenecen a los jueces eclesiásticos, sea excomulgado $»^{30}$.

Los cánones confirman otras características del modelo matrimonial eclesiástico que, no por muy conocidas, deben dejarse de señalar, a saber: que se trata de una unión exclusiva de un hombre con una mujer y que crea un vínculo indisoluble. Además de responder a una práctica consuetudinaria, de adecuarse a la tradición (cuestión nada desdeñable en una época de mudanzas como fue el siglo XVI), lo que la Iglesia parecía ofrecer era una institución que contribuía a mantener el orden establecido, que procuraba la reproducción

23 Gaudemet, 1993: 329.

24 Montero Gutiérrez, 1945: 298-299. Jedin, 1981: 238-242. Carreras, 2002: 87.

25 Casey, 1990: 142-143. Gaudemet, 1993: 328-329.

26 Dedieu, 1984: 274.

27 Harrington, 1995: 25-47. Casey, 2001: 36-45. Rodríguez Sánchez, 1996.

28 Carreras, 2002: 88.

29 Gaudemet, 1993: 335-352.

30 Sacrosanto, Ecuménico y General Concilio de Trento, sesión XXIV, 11-11-1563. 
social del sistema. Ella misma se colocaba como su principal garante, profundizando en un sistema moral y programa de control social tutelado y vigilado por la institución eclesial. La unión matrimonial monógama y permanente en cierto sentido evitaba los posibles enfrentamientos que pudieran surgir entre los grupos de parentesco a causa de divorcios, repudios o bigamias, todo relacionado, como bien ha señalado James Casey, con los códigos de honor sexual vigentes y con las transferencias patrimoniales ${ }^{31}$. La contrapartida fue que se trasladaban los conflictos al interior de las familias y allí pocas veces la Iglesia ofrecía soluciones.

Con todo, el sistema de control social diseñado por la Iglesia en el Concilio de Trento pasaba por la utilización de herramientas aún más eficaces. Una fundamental era que la Iglesia era la que proporcionaba el ser social. Con la implantación de los libros parroquiales se remarcaba ese carácter de garante del orden establecido que ya se ha mencionado, ella era la que certificaba la identidad de las personas. Todo esto se puede comprobar a la perfección con el tema de la publicidad de los matrimonios, las amonestaciones y la obligatoriedad de los forasteros de traer informes de su parroquia originaria. La filosofía quedó establecida de forma clara en el capítulo VII del Decreto de Reforma que trataba de los matrimonios de los vagabundos ${ }^{32}$.

En fin, fue la Iglesia la que diseñó todo un sistema moral basado en el control de la sexualidad. De ahí las condenas tridentinas de las relaciones sexuales extramatrimoniales, del concubinato, de los raptos o de cualquier otra transgresión al modelo matrimonial que había establecido. Que el Santo Oficio de la Inquisición acabara tratando causas de bigamia $-\mathrm{y}$, en general, cualquier desviación de las normas tridentinas - denota el grado de implicación de las estructuras eclesiásticas, y también de las estatales, en este programa moralizante y moralizador ${ }^{33}$.

En última instancia, el control social y la vigilancia sexual llevó a la Iglesia a enfrentarse con otras instancias que, en un momento dado, pudieran llegar a poner en peligro el orden social establecido. Su principal oponente no habría

31 Casey, 1991: 155-156.

32 Concilio de Trento, sesión XXIV, 11-11-1563: «Muchos son los que andan vagando y no tienen mansión fija, y como son de perversas inclinaciones, desamparando la primera mujer, se casan en diversos lugares con otra, y muchas veces con varias, viviendo la primera. Deseando el santo Concilio poner remedio a este desorden, amonesta paternalmente a las personas a quienes toca, que no admitan fácilmente al Matrimonio esta especie de hombres vagos; y exhorta a los magistrados seculares a que los sujeten con severidad; mandando además a los párrocos, que no concurran a casarlos, si antes no hicieren exactas averiguaciones, y dando cuenta al Ordinario obtengan su licencia para hacerlo».

33 Dedieu, 1984: 274-294. 
de ser otro que los grupos de parentesco, a los que, desde la Edad Media, intentaba dominar pues, como señalara Ariès, la Iglesia siempre desconfió del sentimiento del linaje ${ }^{34}$. Para debilitarlo y controlarlo se valió de la teoría de los impedimentos; lo que, además, redundó en su propio beneficio, tal y como sostiene la sugerente tesis de Jack Goody sobre el enriquecimiento eclesiástico y que también podría corroborar Jacques Le Goff ${ }^{35}$.

El porqué de la oposición a los grupos de parentesco también ha de buscarse en la propia tradición de la Iglesia puesto que, ya desde San Agustín, se vio al matrimonio como la vía más adecuada para facilitar la alianza de familias. Comoquiera que los grupos de parentesco buscaban su propia reproducción biológica y social, una excesiva endogamia acabaría por anquilosar el sistema social, pudiendo ponerlo en peligro de extinción. Con la teoría de los impedimentos, la Iglesia lograba poner coto a las tendencias centrífugas de los grupos de parentesco y al erigirse en la instancia que permitía, mediante la necesaria dispensa, burlar la norma restrictiva, acababa por convertirse en el principal mecanismo regulador y controlador del orden social.

Por otro lado, tampoco hay que olvidar algo que ya se ha señalado y que tiene que ver con la tradición consensualista vigente en la Iglesia desde la Edad Media. Práctica que hacía necesaria e imprescindible la libertad de los contrayentes, algo del todo contrario a los intereses de los linajes y grupos de parentesco. La propia inconcreción e indefinición del Decreto Tametsi sobre los matrimonios clandestinos y el consentimiento paterno, además de marcar distancias con las prácticas que habrían de seguir las iglesias reformadas, pueden interpretarse como exhibición del poder de la Iglesia sobre la sociedad. Lejos de atender las demandas sociales o de autorizar unas prácticas generalizadas, la Iglesia se presenta como la verdadera hacedora del orden social, por encima de padres, de grupos de parentesco, incluso de gobiernos. La consecuencia final de todo esto es que, durante la edad moderna, los tribunales diocesanos tuvieron que entender numerosos procesos matrimoniales en los que quedaba de manifiesto la incapacidad eclesiástica para imponer el modelo tridentino, ya en la Península Ibérica, ya en América ${ }^{36}$.

La conclusión del control eclesiástico se puede perfilar con total exactitud cuando se diseña y justifica la superioridad social del clero, lo que le permitiría dirigir la sociedad. La dominación y el carácter privilegiado del clero nacían, en primer lugar, por ser el mediador entre la divinidad y los hombres.

\footnotetext{
34 Ariès, 1987a: 470.

35 Goody, 1981. Las tesis de Goody han sido refutadas en parte por: Brundage: 598 y ss.

36 Campo Guinea, 1998; 2005: 197-210. Seed, 1991. Rodríguez, 1991. Castañeda, 1989.
} 
Pero, además, por su estado, por su condición superior, tal y como definió el décimo canon tridentino sobre el matrimonio:

«Si alguno dijere, que el estado del Matrimonio debe preferirse al estado de virginidad o de celibato; y que no es mejor, ni más feliz mantenerse en la virginidad o celibato, que casarse; sea excomulgado» ${ }^{37}$.

Gracias a su pureza, a su sabiduría, a su contacto con Dios, la Iglesia tenía potestad para actuar sobre la sociedad porque estaba al margen de ella; mejor dicho, porque estaba por encima de ella. El Concilio de Trento, entre sus muchas intenciones, se fijó el objetivo de alejar de forma tajante el estado clerical del seglar ${ }^{38}$. El éxito de su misión dependía de despegarse y alejarse de los asuntos mundanos para, de esta suerte, poder aconsejar y dictaminar sobre ellos. De tal forma que la Iglesia construyó todo un discurso para dominar la sociedad. Pero, por desgracia para ella, en el Antiguo Régimen hubo otras fuerzas que se empeñaron en cercenar sus pretensiones monopolísticas.

\section{LA FAMILIA COMO MOTIVO DE INTERÉS PÚBLICO EN LA AMÉRICA HISPANA}

Así pues, lo que sucedió fue que, justo cuando la Iglesia había logrado asentar de forma definitiva su doctrina sobre el matrimonio, su tradicional monopolio empezó a quebrarse, no sólo por la aparición de las Iglesias reformistas, sino, sobre todo, por la consolidación del Estado. De tal forma que las Monarquías empezaron también a intervenir en la cuestión matrimonial: se inauguraba la vía seglar ${ }^{39}$. Hasta cierto punto puede decirse que fue una consecuencia lógica de la propia fijación conciliar: una vez que se establecía de manera indubitable el carácter sacramental del matrimonio, la intervención eclesiástica se circunscribía a este aspecto, lo que permitía entrar en otras parcelas sin cuestionar la autoridad religiosa ni el vínculo creado. Así, la Monarquía incidió en aquellas cuestiones relacionadas con el matrimonio sobre las que ya había legislado, al tiempo que le permitía entrar en los espacios claroscuros que había dejado Trento: la celebración, la publicidad, la autoridad paterna, la herencia ${ }^{40}$. Fue el Estado, ya en la Edad Media, el primero que saltó desde el matrimonio para llegar a la familia. Y la familia era una realidad poliédrica: una comunidad de bienes, una unidad de producción, un espacio de rela-

37 Sacrosanto, Ecuménico y General Concilio de Trento, sesión XXIV, 11-11-1563.

38 Domínguez Ortiz, 1973: 239. Contreras, 35 (Valencia, 1999): 3-22.

39 Gaudemet, 1993: 353-369.

40 Bonfield, 2002: 153-203. 
ción; comunidad de sangre, una unidad de transmisión, un sentimiento, una idea...

De esta forma, el valor sociopolítico, económico, cultural y moralizante asignado a la familia contribuye a explicar que cada aspecto que regía las relaciones de las parejas legítimas estuviera en el marco legal estrictamente controlado y prescrito por la Iglesia y el Estado. En efecto, desde la óptica del poder temporal, el matrimonio y a través de éste la organización familiar, aseguraba la reproducción del sistema social, el crecimiento demográfico de la Monarquía y constituía un instrumento importantísimo de control del orden social, fundamento de la dominación colonial en el Nuevo Mundo. Consecuencia de ello resulta el trasplante desde la metrópoli de las numerosas instituciones vigentes en la península que regulaban y apuntalaban dicha institución, entre ellas la dote, las arras, los esponsales, la patria potestad, la figura de la autoridad marital, la tutela, la curatela, la normativa que regulaba testamentos y codicilos.

Motivo de especial preocupación resultaba para la Monarquía la desintegración de los grupos familiares en la Península al producirse la emigración del jefe hacia las Indias. Profusa legislación emanada de la Corona durante todo el período colonial, aunque de difícil aplicación, tendió a la reunión de dichos grupos, ya fuere a través de la instalación de esas familias en América, ya a través del regreso del padre a su país de origen. La Iglesia apoyaba de hecho esta política ordenando a los obispos se llevase estricto control en las parroquias levantando nóminas conteniendo los nombres de los individuos casados, a fin de promover tras un cierto tiempo, su regreso a España. Una forma de alentar el casamiento de los solteros - entre otros fines para promover el poblamiento de las áreas descubiertas - consistía en exigir estado de casado para acceder a determinadas funciones del Estado.

Medidas que pretendían asegurar la formación de familias legítimamente constituidas y estables, procurar la vida en común de los casados; evitar la bigamia; desalentar el arraigo en América de súbditos casados sin sus cónyuges; prohibir la utilización de la institución matrimonial con fines ajenos a su naturaleza; evitar que pasasen a Indias mujeres solteras solas, formaron parte de una política tendente a impedir que las áreas de la península emisoras de población se transformasen, en síntesis, en un reservorio de familias desintegradas, esposas abandonadas, hijos librados a su suerte. Y que, a por su parte, los territorios americanos en proceso de colonización se convirtieran en un reducto de adúlteros, bígamos, hijos extramatrimoniales, prostitutas. En definitiva, lo que se pretendía era propender a la paz y el orden evitando el caos social ${ }^{41}$.

41 Icaza Dufour, 1987: 517 y ss. 
El asentamiento de grupos familiares, en tanto que factor de estabilización y arraigo de la población en tierras americanas, resultaba de singular importancia para la Corona: hombres encargados de proporcionar el sustento de su prole, madres ocupadas en parir, criar y educar a los hijos de legítimo matrimonio, eran garantes del aumento de las poblaciones y promoción de riqueza del Reino. Un buen gobierno implicaba, pues, propender a la estabilidad de las familias en aras de la paz y prosperidad en ambas sociedades, la de origen y la receptora.

Durante los tiempos de la conquista el matrimonio fue utilizado en no pocos casos como un instrumento de dominación política de las sociedades que se pretendía someter. En efecto, el casamiento de español con hija de cacique o principal de una comunidad aborigen constituyó en ciertas circunstancias una singular estrategia para favorecer el control de una población. Al mismo tiempo, fue para la Iglesia una de las primeras herramientas de evangelización de la población aborigen en el Nuevo Mundo. Con todo, una de las consecuencias, algo seguramente paradójico como indica Rosario Estinou ${ }^{42}$, fue que la introducción del modelo matrimonial católico en América impulsó y alentó no pocas uniones situadas al margen de la norma, como muy bien ha demostrado Pilar Gonzalbo en no pocos trabajos ${ }^{43}$.

Con el tiempo, el estado de casado fue constituyendo en la América española un indicio de una inserción social exitosa y un significativo instrumento de movilidad social. Así por ejemplo, al estudiar a la clase mercantil de Buenos Aires Susan Socolow observó que en 1778 el 76\% de los comerciantes preeminentes estaba casado y que el $12 \%$ de ellos se casaría más tarde ${ }^{44}$. Poseer casa poblada, acceder a un matrimonio con una joven criolla de buen lina$\mathrm{je}$, en lo posible con una buena dote, ser padre de una abundante progenie que asegurase la continuidad del apellido y de los negocios familiares; ejercer la potestad sobre la esposa, hijos y numerosos dependientes libres o esclavos y otros agregados era interpretado como un símbolo del status social eminente alcanzado. Constituirse pues en cabeza y sostén de un hogar abundantemente poblado, complejo en su composición, con numeroso servicio doméstico otorgaba honorabilidad y prestigio social, y no accedía a ello quien simplemente lo deseaba sino quien efectivamente había desplegado satisfactoriamente las estrategias para lograrlo.

42 Esteinou, 3 (México, 2004).

43 La producción de esta autora es ingente, así como la calidad de sus aportaciones; por citar sólo algunos de sus últimos trabajos, véanse: Gonzalbo Aizpuru, IX (New Mexico, 2000): 7-19; 2004: 121-140.

44 Socolow, 1991: 51. 


\subsection{La visión del matrimonio y la familia desde la Audiencia Episcopal de Córdoba, Argentina}

La Iglesia católica estuvo presente desde los primeros momentos de la conquista española en América donde también desplegó su inmenso poder. Dada su misión evangelizadora, era la única institución que a través de las parroquias controlaba y conocía tanto las comunidades urbanas como rurales del Nuevo Mundo $^{45}$. Su misión de transmitir la fe fue un objetivo compartido con la Corona española. El derecho otorgado por el Papa a la Monarquía española a percibir los diezmos de la Iglesia en 1501 y unos años después el otorgamiento del Patronato Universal sobre la Iglesia de Indias redundaría en la práctica en una ampliación de la labor eclesiástica sumándose a su obra evangelizadora, una acción de transmisión cultural y de importantes aspectos de la organización y control de la nueva sociedad, como fue la implantación del modelo matrimonial tridentino ${ }^{46}$.

Entre los siglos XVI al XIX en la actual Argentina existieron las diócesis del Tucumán y la del Río de la Plata. Desde el siglo XVII éstas formaron parte del arzobispado de Charcas, donde residía el arzobispo o metropolitano ${ }^{47}$. La jurisdicción del Obispado del Tucumán, que nos ocupa en este trabajo, estaba integrada por una vastísima región que abarcaba $4.000 \mathrm{~km}$. e incluía a Jujuy, Salta, Tucumán, Santiago del Estero, La Rioja, Catamarca y Córdoba. En 1806 fue erigido el Obispado de Córdoba propiamente dicho, éste tomó la conformación de la Gobernación Intendencia de ese nombre abarcando a Córdoba, San Juan, Mendoza, San Luis y La Rioja.

Como se lleva expresado más arriba, en el Concilio de Trento se había dispuesto que constituía parte de las funciones de la iglesia llevar registro escrito de los hechos vitales de la población. La diversidad étnica que caracterizó a la sociedad hispanoamericana colonial hizo que su labor de asignación de la identidad social cobrase en estas tierras especial significado e importancia fortaleciendo el papel que desplegaba en la sociedad. La limpieza de sangre era exigida para el acceso a dignidades eclesiásticas, a altas funciones de gobierno, franqueaba oportunidades de educación superior y abría camino para el ascenso económico. En Córdoba, en algunas parroquias de la ciudad y de la campaña se llevaban diferenciadamente los registros vitales de la población siguiendo un criterio socio-étnico, pudiendo asentarse a españoles - peninsulares y criollos - y naturales — indios, negros y mezclas - ya sea en el mismo

\footnotetext{
45 Arretx, Mellafe y Somoza, 1983: 17.

46 Latasa, 2005: 237-256.

47 Di Stefano, R. y Zanata, L., 2000: 52.
} 
libro, en una primera y segunda parte, o en en tomos diferentes reservados a uno y otro grupo ${ }^{48}$. Coherente con ello, la inscripción por el párroco de un recién nacido en el libro correspondiente al tiempo que otorgaba identidad, definía en buena medida en la práctica, en una sociedad jerarquizada como la tratada, el destino social de esa persona. La «calidad» de la persona ${ }^{49}$ podía ser modificada por el párroco al momento del matrimonio, lo que permitía que en ciertos casos, individudos de sangre mezclada pudieran ser «blanqueados», teniendo pues los ministros de la Iglesia capacidad de incidencia en los procesos de movilidad social ${ }^{50}$. Es posible que por fuerza de la tradición y la costumbre, en el caso de la ciudad de Córdoba, como observara Celton para la parroquia de la Asunción de Nuestra Señora (Catedral), los registros vitales de los fieles fueron asentados separadamente hasta una fecha tan tardía como $1870^{51}$, ya en pleno proceso de secularización social, y veinte años después del dictado de la

48 En la ciudad de Córdoba, en la Parroquia La Asunción de Nuestra Señora (Catedral) existían libros separados para bautismos, matrimonios y defunciones de españoles (blancos y criollos) y naturales (todos los demás) hasta 1874 y de confirmaciones hasta 1854. En el área rural, en la parroquia Inmaculada Concepción de San Vicente (curato de Punilla) existía un solo libro de bautismos, matrimonios defunciones y confirmaciones donde se asentaba diferenciadamente, hasta principios del siglo XIX, en la primera parte los datos de españoles y en la segunda los de naturales. En San Agustín (curato de Calamuchita) se llevaban dos libros separados para bautismos de españoles y naturales hasta mediados del siglo XIX y para matrimonios hasta principios del siglo XIX. En Villa del Rosario (curato de Río Segundo) los bautismos estaban diferenciados en dos tomos para españoles y naturales y los libros de defunciones también llevados separadamente denominaban a los sectores no españoles como «gente de servicio» hasta fines del siglo XVIII y hasta 1840 bajo la denominación de españoles y naturales.

49 Adherimos al concepto de «calidad» de la persona propuesto por Pilar Gonzalbo Aizpuru para referirnos a la valoración social de los individuos en la sociedad colonial, por considerarla la más completa en tanto incluye consideraciones de raza, dinero, ocupación, respetabilidad individual y familiar: Gonzalbo Aizpuru, 1998: 13. La denominación de «clase» utilizada también en el texto se vincula a la identificación socio-étnica utilizada en la época en los padrones de población de Córdoba correspondientes a 1778, 1813, 1822 y 1832, en los cuales se utiliza esta designación para registrar la población diferenciando al «español» o «noble» de «indio», «negro» y otros subtipos como el denominado «pardo», vocablo muy frecuentemente utilizado en la sociedad tratada para designar a los individuos de sangre mezclada. La columna correspondiente a la «clase» es omitida ya en la mayor parte del padrón de 1840, lo cual interpretamos como indicadora de una flexibilización en las percepciones socio-étnicas. No obstante dicha tendencia, alusiones a las diferencias sociales siguieron siendo remarcadas por los censistas acompañando a los datos referidos a la condición jurídica de la persona epítetos tales como: «pleve» o «pleveyo» (sic) diferenciando a estos individuos de los que continúan siendo identificados como españoles o bien, como «nobles» Ghirardi, 2007.

50 Ferreyra, 2005: 95.

51 Celton, 1997: 328. 
constitución nacional, y a sesenta años de la obra legislativa de tinte democratizante de la Asamblea del año XIII.

La comunicación entre los representantes de la Iglesia y los fieles en los territorios evangelizados era esperable que fuera estrecha y cotidiana - lo cual no ocurría necesariamente en la práctica - acorde a la posición rectora y hegemónica que pretendía en la sociedad. La presencia de su delegados era necesaria en los momentos más trascendentes de la vida de cada uno de los integrantes de una familia: bautismos, confirmaciones, matrimonios, administración de la extremaunción y entierros. Se pretendía que el sacramento de la confesión constituyese además un ascendiente poderoso en el moldeamiento de la conciencia de los fieles, con arreglo a la moral y a las normas canónicas. Al menos en las ciudades donde la proximidad espacial favorecía los encuentros, la misa dominical, las procesiones en los días de celebración que indicaba el año litúrgico, las visitas a la Iglesia, los requerimientos de los fieles a los religiosos sobre las más variadas cuestiones, desde asesoramiento médico hasta búsqueda de amparo físico y espiritual, constituían eventuales motivos de aproximación de la población a los hombres de la Iglesia sin olvidar que en las clases preeminentes vínculos de sangre unían a la Iglesia además, a las familias que habían entregado uno o varios de su hijos al servicio de Dios ${ }^{52}$.

\subsection{La defensa de la integridad del matrimonio}

En el diseño de ordenamiento y reproducción del sistema social concebido por la Iglesia y refrendado por la Monarquía católica destaca en las fuentes consultadas la institución matrimonial. Desde esta óptica, cualquier amenaza a la integridad del vínculo era interpretada como atentado a la paz, orden y perpetuación de la sociedad misma. El divorcio o quiebra del estado matrimonial estaba autorizado por el Derecho canónico del matrimonio sólo en dos moda-

\footnotetext{
52 Tómese como ejemplo de lo señalado la asistencia solicitada por don Francisco Váquez Maceda al padre Lector, fray Pedro Luis Pacheco, de la Orden de San Francisco al tomar conocimiento de la preñez de su distinguida novia, doña Isabel Gigena. Francisco le visitaría en su celda, donde le rogaría que concurriese al domicilio de Isabel a fin de examinarla, reiterándose sus consultas al religioso en varias oportunidades por el mismo motivo: Archivo del Arzobispado de Córdoba (AAC) Juicios de Esponsales, Legajo 193 (1797-1798) t. V, expediente único. Un tratamiento completo de esta causa se encuentra en: Ghirardi, XII/4 (New Mexico, 2003). Los casos de maltrato conyugal en los cuales las esposas lastimadas o allegados de éstas concurrían al cura a solicitar amparo y asistencia, del mismo modo que los de jóvenes desfloradas y abandonadas luego por sus parejas que iban a denunciar su situación a la Iglesia y que concluyeron en demandas judiciales constituyen testimonio del frecuentamiento que tenían fieles de distintos sectores sociales con representantes de la Iglesia.
} 
lidades, como nulidad o divorcio quoad vinculum, cuando se establecía la disolución del lazo sagrado o se demostraba que éste no había existido, permitiendo un nuevo matrimonio a la pareja; y la separación de cuerpos, también conocida como de lecho y mesa o divorcio quoad thorum et mutuam cohabitationem, en cuyo caso el vínculo entre los esposos persistía tras la separación, estándoles interdicto contraer nuevas nupcias. Ambos — nulidad y separación- eran difíciles de alcanzar y su autorización se permitía sólo en casos excepcionales $^{53}$.

La firme defensa de la indisolubilidad del lazo nupcial, derivada del carácter sacramental del matrimonio religioso es recogida por las fuentes consultadas y se refleja con especial evidencia en las dificultades para divorciarse existentes en la jurisdicción estudiada según surge del análisis de las causas matrimoniales. En efecto, según el análisis efectuado por Ghirardi, las demandas judiciales de divorcio aceptadas por el tribunal eclesiástico de la diócesis de Córdoba - 31,7\% de las mismas consistían en solicitudes de nulidad matrimonial (68) y 68,2\% (146) en pleitos de separación de cuerpos - alcanzan un promedio general de 1,3 causas gestionadas por año entre 1688 y 1850 en los territorios comprendidos en la ciudad y campaña de Córdoba y el resto de las provincias que integraban el obispado ${ }^{54}$. En ese sentido, es necesario aclarar que posiblemente debido a la proximidad a la sede del tribunal, el grueso de las mismas provenían del territorio cordobés, especialmente del campo - alrededor del $80 \%$ de la población cordobesa residía en el área rural- y sólo un $6 \%$ de las separaciones y algo más del $12 \%$ de las causas de nulidad matrimonial provenían de las otras provincias ${ }^{55}$.

53 Un trabajo pionero acerca de la regulación del matrimonio y su quiebre en Indias puede consultarse en Rípodas Ardanaz. Rípodas Ardanaz, 1977: 383 y ss.

54 Ghirardi, 2004: 217 y ss. La mencionada autora contabilizó 214 expedientes de divorcio conservados advirtiendo acerca del extravío al menos de un tomo correspondiente al período 1790-95. El promedio de divorcios anuales calculado por Ghirardi surge de dividir el total de expedientes identificados en el Archivo del Arzobispado de Córdoba (214) con el período de años comprendidos en el presente análisis: 162 solicitudes entre 1688 y 1850. Estos datos se pueden comparar con los obtenidos para otras regiones. En el Río de la Plata el promedio era de 3,71 divorcios tramitados por año para el período colonial: Mallo, 42 (Buenos Aires, 1992): 378. En Lima, el promedio de conflictos por año ascendía a 31,2 divorcios por año en el período 1651-1700 y a 14,3 entre 1760 y 1810: Lavallé, 4 (Cuzco, 1986): 428 y ss.; y Flores Galindo y Chocano, 2 (Cuzco, 1984): 405. En México Pilar Gonzalbo contabilizó 1 caso promedio por año en las primeras décadas del siglo XVIII aumentando luego a 6 anuales en el último tercio de la misma centuria: Gonzalbo Aizpuru, 1998.

55 Ghirardi, 2004: 217 y ss.

Globalmente, considerando ciudad y campaña, la población de Córdoba reunía según el censo de 1778 la cantidad de 43.511 habitantes residiendo en la ciudad 7.320. Para 1840, fecha 
Si bien se ignora el número de matrimonios correspondientes a la campaña de Córdoba en el período estudiado, a partir de los trabajos de Ferreyra y Celton ${ }^{56}$ conocemos el volumen total de casamientos efectuados en la ciudad entre 1700 y 1839 . De la relación entre el número de pleitos de divorcio de la la ciudad con el total de uniones en la misma surge que menos de un $1 \%$ de los casamientos aparejó un conflicto provocando una demanda de separación o nulidad en ese período ${ }^{57}$. Se entiende que dicha proporción está subestimada ya que al menos un tomo que contenía las causas matrimoniales de fines del siglo XVIII, época en la que se observa un significativo incremento de las demandas, no se conserva en los repositorios del archivo de la curia. Al mismo tiempo, una relativamente baja proporción de pleitos tramitados ante la justicia, en relación a los matrimonios efectuados no se correlaciona necesariamente con una escasa conflictividad conyugal real. Comparativamente, en México, Arrom observa un promedio de 15 divorcios por año a fines del siglo XVIII constituyendo éstos el $1 \%$ de los matrimonios legales, lo cual se asemeja bastante a los resultados obtenidos para la sociedad tratada ${ }^{58}$.

En cuanto a la factibilidad de obtener el divorcio a través de una sentencia favorable, del total de las causas tramitadas, incluyendo ciudad y también campaña de Córdoba y otras provincias del obispado, sólo un 10\% de las solicitudes de nulidad matrimonial alcanzaron una sentencia favorable; y un 11\% de las de separación de cuerpos culminaron en autorización de interrupción temporal o perpetua de la convivencia. Ello es demostrativo de una política de firme defensa de la institución matrimonial mantenida por el tribunal de la Audiencia episcopal de la jurisdicción tratada a partir de su renuencia a autorizar judicialmente la quiebra de la unión, aprobándola sólo en circunstancias excepcionales, dentro de la ya excepcionalidad de las solicitudes presentadas para alcanzarlo.

Contrasta con la relativa escasez de expedientes de divorcio tramitados, la amplia gama de impedimentos considerados capaces de constituir motivo de nulidad de un matrimonio que el tribunal eclesiástico reconocióo ${ }^{59}$. Entre ellos

cercana al fin de la observación efectuada en este trabajo, la población total de la provincia de Córdoba había aumentado a 100.652 habitantes. Desde el punto de vista del asentamiento poblacional, el 86,3\% se concentraba aún en el área rural, cfr. Celton, 1982: 193.

56 Ferreyra, 1997; Celton, 1997.

57 Dicha proporción surge de la diferencia que surge entre los 46 divorcios identificados para la ciudad (entre nulidades y separaciones separaciones de cuerpos) y 7.474 casamientos efectuados en el área urbana — 46/7.474-: 0,61\%.

58 Consultado en Mallo (Buenos Aires, 1992): 378.

59 Los impedimentos establecidos por la Ley canónica se dividen en dos categorías: dirimentis, los más serios ya que involucraban la nulidad del matrimonio en caso de transgresión: incluían la impubertad, la bigamia y el parentesco por consanguinidad y afinidad. Los impedi- 
y en el siguiente orden de importancia se aceptaron como causales de las demandas de nulidad: la bigamia; el parentesco en grado prohibido por afinidad y consanguinidad; los defectos de forma canónica; la coacción y fuerza en la celebración del casamiento; el matrimonio secreto sin los requisitos de publicidad exigidos; la imposibilidad de la consumación; el error en la condición jurídica de la persona; el impedimento por crimen. Algunos autores como Salinas Álvarez han sugerido que los interesados en alcanzar la nulidad de su matrimonio se vieron siempre obligados a utilizar ante la Iglesia argumentos sofísticos, es decir fingidos con sutileza, dada la dificultad existente en el pasado para lograr el divorcio ${ }^{60}$. Ignoramos si ello pudo ser así en la totalidad de los casos, pero de ser verdadero serían los mismos hombres de la iglesia, empapados de las normas canónicas, quienes asesorarían a las parejas sobre la viabilidad del causal a interponer, contribuyendo, de hecho en la práctica a acciones atentatorias del principio de indisolubilidad del matrimonio sostenido por la institución eclesiástica en casos de conflictividad extrema de la vida familiar.

La aplicación de violencia y miedo al momento de la celebración del casamiento, pero fundamentalmente las uniones en las cuales se demostró la existencia de bigamia, entremezcladas con cuestiones de parentesco en grado no dispensable y defectos de forma canónica, fueron causales que justificaron sentencias aprobatorias de la nulidad del matrimonio. Interesa destacar que fueron objeto de anulación, tanto matrimonios conformados por parejas representantes de la clase acomodada como pertenecientes a los sectores subalternos ${ }^{61}$.

El peligro de vida y el adulterio asociado a extrema crueldad física, la demencia combinada con disipación de bienes y trato injuriante constituyeron el fundamento del tribunal para decidir el divorcio perpetuo de algunas parejas, criterio que se reitera en los escasos casos de separación temporal. Del mismo modo, las pocas sentencias favorables a separaciones perpetuas, también involucraron tanto a parejas de modesta extracción social como a otras integradas por blancos de situación acomodada ${ }^{62}$.

La decisión de revalidación del matrimonio en las causas de nulidad y la de reconciliación de las parejas en los pleitos de separación sobresale como polí-

\footnotetext{
mentos impedientes tenían menor gravedad que los anteriores ya que su incumplimiento no implicaba la anulación del vínculo y prohibían la celebración del matrimonio en los tiempos sagrados señalados por el calendario religioso - épocas de cuaresma y adviento- y los realizados sin la correspondiente publicidad — bandos y proclamas - Socolow, 1991: 134.

60 Salinas Álvarez, 1994: 65.

61 Ghirardi, 2004: 296 y ss.

62 Ghirardi, 2004: 395.
} 
tica de la Iglesia en las causas matrimoniales cuando existió sentencia. Una vez más, ello es demostrativo de la voluntad de defensa de la integridad y estabilidad de la institución matrimonial y consiguientemente de la familia legítima $^{63}$.

El respeto a las decisiones de la máxima autoridad judicial de la diócesis con sede en Córdoba se pone de manifiesto en la escasez de recursos de apelación utilizada por los fieles que surge del análisis de las causas matrimoniales, hecho acentuado además seguramente por los costos del trámite, la lentitud de los procedimientos que implicaba su tramitación ante el metropolitano de $\mathrm{La}$ Plata, y las grandes distancias. Algunos de los escasos intentos de modificación de la sentencia otorgada en primera instancia fueron accionados por las mujeres solicitantes del divorcio, aunque los resultados obtenidos fueron modestos $^{64}$.

Más de la mitad del total de causas iniciadas ante los tribunales eclesiásticos - siempre en la sociedad estudiada y según la documentación consulta$\mathrm{da}$ - tanto por cuestiones relativas a nulidades matrimoniales como a solicitudes de divorcio quoad thorum, no se resolvían. En efecto, casi un 70\% de los juicios de separación de cuerpos permanecieron inconclusos; al mismo tiempo, alrededor del $62 \%$ de las acciones de nulidad presentadas quedaron paralizadas en alguna de sus etapas procesales. Cabe preguntarse si ello se debía a dificultades intrínsecas al funcionamiento del aparato institucional eclesiástico, sobrecargado de funciones, o a causas externas. La exclusividad del ejercicio de la justicia ordinaria depositada en la persona del obispo, compartida solamente con el provisor, quien obtenía de aquél la potestad de juzgar en su nombre, constituyendo ambos un único tribunal sin poder extenderse el poder judicial a ningún otro organismo eclesiástico salvo expresa excepción a pedido del rey ${ }^{65}$, aunque beneficiosa en cuanto a la uniformidad del criterio judicial utilizado, favorecería la acumulación de pleitos que esperaban su personal tratamiento, dificultándose su sustanciación. Ello se agravaría en épocas particularmente turbulentas desde el punto de vista político-militar como las que corresponden a ciertos períodos que tratamos como consecuencia de la quiebra de la dominación colonial y posteriores conflictos civiles por la organización del país. No debe descartarse además la intencionalidad de ciertas postergaciones indefinidas de dictado de sentencia como parte de una política consciente

63 Un 25\% del total de los pleitos de nulidad presentados en el períodod estudiado culminaron en la revalidación de la unión y en un 19\% del total de pleitos de separación de cuerpos se sentenció la reconciliación de la pareja, cfr. Ghirardi, 2004: 292 y 395, respectivamente.

64 Ghirardi, 2004: 298 y 405, respectivamente.

65 Dellaferrera, 9 (Córdoba, Arg., 2000): 137-148, en especial, 142-143. 
de la autoridad actuante de denegación de hecho del divorcio y desaliento de nuevas solicitudes. En ese sentido, Lavallé ha señalado que las fluctuaciones en el número de demandas de divorcio aceptadas por la Audiencia episcopal en Perú a través del tiempo pueden asociarse al menos en parte a políticas de la Iglesia de mayor o menor flexibilidad ${ }^{66}$.

No se ha detectado que la suspensión de los procesos esté asociado a algún causal específico, ni en las separaciones de lecho y mesa ni en las cuestiones de nulidad ya que se observa en toda su diversidad: cuestiones de bigamia, impedimentos de consanguinidad, casamientos secretos, ejercicio de violencia y miedo, sevicia y malos tratamientos, adulterio y otras ${ }^{67}$.

Al iniciarse el pleito de divorcio la pareja era separada por el tiempo que durase el juicio y la mujer era puesta en depósito judicial en casa honrada, prohibiéndose al marido aproximarse a ese domicilio. Cuando el juez eclesiástico no hacía lugar a la solicitud de la separación por considerar según su criterio que no existían razones suficientes se ordenaba la salida de la mujer del depósito y la restitución al hogar conyugal lo cual ocasionaba su fuga en ciertos casos, las mujeres solían escapar también durante el pleito sin esperar su sustanciación, lo cual era interpretado por la autoridad como escandaloso ultraje al juzgado eclesiástico motivando orden de captura.

Respecto de los procedimientos utilizados en los transgresores a las normas morales del matrimonio, la práctica judicial demuestra que la justicia secular acudía, tanto en el campo como en la ciudad, en apoyo de la Iglesia, a fin de reconvenir a los reos, prenderlos y encarcelarlos según fuera necesario. Penas específicamente canónicas fueron la excomunión mayor en casos severos, además los ejercicios espirituales, la prestación de servicios comunitarios y otros castigos ejemplificadores como sostener una antorcha encendida al costado del altar durante los oficios principales por un tiempo estipulado. Estas penas coexistían con otras de índole más secular como multas, destierro, azotes y cárcel aplicados por la justicia Real68.

El matrimonio es presentado en los expedientes eclesiásticos correspondientes a la Audiencia episcopal de Córdoba como «el camino que deben reco-

66 Según los datos presentados por B. Lavallé, en Perú la gente solicitaba el divorcio con más facilidad en el siglo XVII que en el XVIII. Se observó una disminución notable de casos en Lima en los años finales del siglo XVII y durante la centuria siguiente, en ese sentido, los Obispos de Quito y Cuzco se quejaban de la excesiva facilidad con que las mujeres presentaban demandas de divorcio y nulidad en los últimos años del siglo XVI y comienzos del XVII, cfr. Lavallé, 1986: 430-431.

67 Datos sobre las nulidades y los resultados de los pleitos de separación de cuerpos en: Ghirardi, 2004: 293 y ss. Y 395 y ss., respectivamente.

68 Ghirardi, 2004: 302 y ss. y 401 y ss. 
rrer los cónyuges para servir mejor a Dios», como un «estado ideal» e incluso como «el más bello vínculo existente en la sociedad». Ingredientes constitutivos de la vida maridable que se reiteran en el discurso eclesiástico son: la paz, la estabilidad, la apasibilidad, la quietud, la tranquilidad doméstica, el sosiego, la fidelidad y la unidad de domicilio que debían guardar los casados.

\subsection{La moral de las relaciones familiares desde los discursos de la Iglesia}

Respecto del sistema conyugal y posición hacia la mujer que emanan desde los discursos de la documentación eclesiástica consultada, se corrobora la afirmación de Del Priore para los estudios en Brasil respecto de la jerarquía y la obediencia como notas sobresalientes que debían caracterizar las relaciones entre los cónyuges ${ }^{69}$. La legitimidad del disciplinamiento de la esposa con fines correctivos y pedagógicos, aunque aplicado con mesura y necesaria caridad cristiana se reitera en los escritos de las partes y se corrobora en los alegatos de los fiscales sin ser contradichos por la defensa femenina. La tolerancia hacia los castigos físicos, aunque «mesurados» aparece compatible con un trato respetuoso esperable entre los cónyuges, de tolerancia y consideración mutua.

Del mismo modo, los argumentos de la fragilidad femenina y su propensión al engaño sirvieron para justificar sus yerros y necesidad de consejo y guía. La importancia de la labor formadora y moralizadora de la juventud, resultó especialmente identificada con el rol materno, así como el resguardo de la reputación de las doncellas de la casa es presentada también como una responsabilidad familiar. El peligro latente de una actitud paterna cobrándose la vida de la joven de familia ante el deshonor de la desfloración y embarazo de hija soltera aparece sugerido como posibilidad que debía prevenirse en más de una oportunidad, en los discursos.

Los niños, si bien mencionados sólo muy tangencialmente en los expedientes, son identificados con una planta tierna cuyos comportamientos precisan ser moldeados a través del ejemplo de las conductas de los padres y de la instrucción cristiana. Algo semejante ocurre con los esclavos, cuyas conductas inconvenientes aparecen en ocasiones atribuidas a una inadecuada o inexistente formación moral del amo. Los excesos sexuales masculinos hallan justificación en la naturaleza fogosa del hombre. Las acusaciones de corrupción en mujeres que aseguraban estado de virginidad anterior al conocimiento carnal con el hombre que las había conocido carnalmente bajo supuesta palabra de

69 Del Priore, 1993: 171-189, la cita en: 176. 
matrimonio y luego abandonado, fueron rebatidas desde el discurso eclesiástico que enfatizaba la importancia de la reputación de virgen en una doncella, «el ser tenida por» sobre la virginidad efectiva de la mujer.

Acorde con las normas vigentes, los tribunales eclesiásticos en la jurisdicción estudiada ofrecieron a las mujeres un espacio donde reclamar una compensación material o simbólica ante situaciones que consideraron abusivas por parte de sus parejas resultantes de relaciones ocasionales o mancebías prolongadas cuando éstos se negaban a casarse con ellas. Ante la Audiencia de Córdoba desfilaron centenares de mujeres de estratos sociales diversos, sus quejas fueron oídas y sus demandas investigadas con una profundidad y atención variable. De las demandas que presentaron, las sentencias fueron favorables a sus pedidos en un $41 \%$ y contrarias en un $33 \%$. El resto finalizó en desestimiento de la acción o transacción de partes ${ }^{70}$.

\subsection{Efectos no deseados para la vida familiar derivados del funcionamiento institucional eclesiástico}

Se observa en la Iglesia una marcada preocupación por velar por el cumplimiento de las normas canónicas en los fieles en relación al matrimonio, aunque con modestos resultados. Desde el poder espiritual se tendía a promover la bendición en el altar de las parejas que manifestasen intención de unirse, constituyendo el mutuo consentimiento de los novios la condición fundamental exigida para consagrar dichas uniones. La labor eclesial estaba orientada a prevenir y desalentar situaciones que pudiesen desembocar en conductas de los feligreses que transgrediesen los preceptos normativos establecidos. Consecuente con ello resulta la penalización de prácticas sexuales marginales al derecho canónico y real tales como el concubinato, la bigamia y otras. Sin embargo, de la lectura crítica de las causas matrimoniales surgen circunstancias en las que la misma Iglesia, tan severa y celosa en teoría por promover los matrimonios, en ciertos casos los desalentaba indirectamente.

Conspiraba contra el programa moralizador de la iglesia en primer lugar el desmesurado tamaño del territorio de la diócesis en sus distintas configuraciones durante el período estudiado. El aislamiento, especialmente en la campaña, la inaccesibilidad de ciertos parajes, las grandes distancias, la inexistencia de lugares fijos para el adoctrinamiento de los fieles, incidían negativamente en la función pastoral dificultando la enseñanza de la doctrina cristiana y la

70 Ghirardi, 2004: 180 y ss. 
administración de los sacramentos, a lo cual se sumaba la escasez de sacerdotes en la diócesis ${ }^{71}$. Por otra parte, la negligencia y desidia de algunos religiosos en el cumplimiento de sus funciones pastorales favorecía el desarrollo de situaciones irregulares, especialmente en zonas alejadas de la sede del obispado donde, como se ha afirmado, resultaba muy difícil efectuar controles. En ocasiones los sacerdotes accedían a celebrar casamientos que no cumplían con los requisitos legales que fijaba la Iglesia ${ }^{72}$. Cuestiones relacionadas con faltas referidas a las formalidades del sacramento matrimonial, sumadas a otras tales como transgresiones al celibato, ebriedad, juego, malos tratos, han sido relacionadas con una cierta relajación de costumbres del clero, a lo que se añadiría en las últimas décadas del siglo XIX un grado de libertad de acción respecto de las autoridades romanas que habría comenzado desde la Revolución y se habría profundizado en la época federal ${ }^{73}$.

Rígidas normas de la Iglesia y aspectos de procedimiento en su funcionamiento institucional ponían en ocasiones en situación de desamparo legal a los actores de uniones ya efectuadas, y a los frutos de ellas derivados. Las causas matrimoniales identificadas como de nulidad por defecto de forma canónica constituyen ejemplo de la situación enunciada. Estaba estipulado que los novios debían contraer nupcias en el ámbito espacial de naturaleza o residencia habitual; de allí que los casamientos celebrados ante párroco extraño eran considerados inválidos para la Iglesia. Con ello se pretendía evitar que personas desconocidas en un lugar incurriesen en transgresiones a los impedimentos que establecía el Derecho canónico en materia matrimonial, tales como casa-

71 Las propias percepciones de los actores de la época sumados a cálculos cuantitativos permiten sustentar la tesis de una relativa escasez de sacerdotes disponibles para el servicio de las parroquias de la diócesis en la segunda mitad del siglo XIX: cfr. Ayrolo, 16 (Tandil, 2001): 426-434.

72 Así, por ejemplo, un sacerdote era acusado de haber desposado a una pareja ajena a su jurisdicción en una causa de nulidad matrimonial, el cura era denunciado además en otro expediente por el Cacique Bartolomé Caliba por la muerte de cuatro personas sin confesión, por su ausencia, cfr. AAC, Causas de nulidad matrimonial, legajo 194, Años 1688-1745, t. I, exp. 12. El ejemplo de de Don Melchor Almancid, Cura y Vicario de La Rioja resulta ilustrativo al respecto: el mismo fue acusado por una mujer de haber casado a su primo «... una noche con una muger desigual y de baja sphera sin amonestación alguna y oi estan separados y no hace vida con su muger; al otro primo [de la misma denunciante] lo caso otra noche en casa de la muger sin amonestación alguna y desde esa hora en que se celebró el matrimonio mi primo no ha buelto a ver a dicha muger que él dice que no es su esposa...», cfr. AAC, Juicios por Esponsales, legajo 193, años 1702-1765, t. I, exp. 5. Para más información y ejemplos sobre el tema véase: Ghirardi, 2004: 459 y ss.

73 Casos de amancebamiento de curas y de pecado de solicitación en: Ayrolo, 16 (Tandil, 2001): 437. 
mientos dobles, o uniones entre consanguíneos o personas afines. El trámite de información matrimonial entrañaba la presentación de testigos conocidos por los aspirantes a unirse, quienes daban prueba de la libertad de los mismos así como de la inexistencia de impedimentos canónicos para realizar el casamiento. Ocurría que en ocasiones los novios, de buena o mala fe se trasladaban a jurisdicciones extrañas para contraer nupcias; los causales de este proceder podían asociarse a situaciones de índole laboral; a la minoridad de los contrayentes que carecían de consentimiento de los padres para casarse; a individuos que contaban con un matrimonio anterior que pretendían ocultar; a casos de rapto, de prófugos de la justicia y otros. Era posible también que por alguna circunstancia el párroco propio les negase el casamiento, ello podía ocurrir por ejemplo con las parejas que vivían amancebadas o presentaban notoria desigualdad de sangre. En relación al primer caso, la Iglesia consideraba que los mancebos eran indignos de contraer matrimonio inmediatamente. Antes de consagrar la unión de individuos que vivían en concubinato debía transcurrir un tiempo de separación en la pareja, a fin de lograr su purificación, ello derivaba en ocasiones en el encarcelamiento de los individuos en cuestión y en el aplazamiento del casamiento por tiempo indefinido hasta autorización del párroco de residencia o de autoridad superior ${ }^{74}$.

Trasladados a otras poblaciones, incluso a otras provincias, con algún ardid los novios conseguían convencer al cura del lugar al que se habían desplazado de que reunían las condiciones exigidas por la Iglesia y eran desposados. Sucedía sin embargo no pocas veces que una denuncia ponía al descubierto la maniobra y el matrimonio quedaba severamente cuestionado. Si bien, como se ha visto, la Iglesia tendía a promover la legitimación posterior de estas uniones, era posible que por alguna razón ésta no tuviese lugar, o se demorase dejando a los contrayentes en una situación marginal a la legislación vigente.

Si bien el Concilio de Trento establecía que las amonestaciones para el matrimonio podían ser hechas por el propio párroco, el Sínodo Diocesano de 1700 habría prohibido, tanto a los curas de la ciudad de Córdoba, como de las

\footnotetext{
74 Una pareja domiciliada en Río Primero fue a casarse a la ciudad de Córdoba porque el cura del lugar dilataba el casamiento debido a que vivían amancebados, ello llevó a los novios a fingir ser naturales de la ciudad, empleando sus respectivos apellidos maternos: AAC, Causas de nulidad matrimonial, legajo 200, años 1803-1810, t. VII, exp. s/n entre 14 y 15 . En otro caso el párroco le negaba el casamiento a una pareja por «notoria desigualdad de sangre y disenso de sus padres». El novio se vio obligado a recurrir al Visitador: «... yo ando huyendo con mi mujer de monte en monte por huir de que me prendan...» solicitaba le fuera revalidado el matrimonio: AAC, Causas de nulidad matrimonial, legajo 198, años 1795-1799, t. V, exp. 4. Informaciones sobre casamientos de mancebos en: AAC, Causas de nulidad matrimonial, legajo 201, años 1811-1814, t. VIII, exp. 10, cfr. Ghirardi, 2004.
} 
restantes del Obispado que las efectuaran sin licencia del obispo o de sus procuradores; del mismo modo, en dicha asamblea diocesana se había establecido también que todos los clérigos, seculares o regulares de estos territorios pudieran administrar el sacramento del matrimonio sin llevar licencia de sus superiores $^{75}$. Por otra parte los regulares tenían prohibida la administración de los sacramentos del bautismo, viático extremaunción y fundamentalmente del matrimonio, a sus familiares ${ }^{76}$. Además la potestad para el ejercicio de ciertas funciones parroquiales - que en ocasiones se hacían por delegación- tenían un término, y si un cura ayudante realizaba un casamiento habiendo expirado el período de su facultad la unión carecía de valor, algo semejante ocurría en los casos en que la delegación de dichas funciones se realizaba sin autorización expresa de la autoridad pertinente. Ello daba lugar a denuncias e impugnaciones varias. En algunos juicios por Esponsales - de spondere, prometer: "prometimiento que hacen de palabra hombre y muger cuando quieren casarse» ${ }^{77}$ - , razones de distribución de funciones hacían que el cura y vicario del lugar no pudiese entender en estas cuestiones ya que las mismas eran privativas del provisor y vicario general del Obispado, lo cual derivaba en conflictos y tardanzas que es de suponer, entorpecían las actuaciones judiciales ${ }^{78}$.

Principios doctrinarios derivados de la indisolubilidad del vínculo matrimonial, determinaron que aun en los casos en que la Iglesia había autorizado separación perpetua, los individuos tuvieran vedada una nueva unión legítima quedando por ende condenados a la soledad o a mantener uniones extramatrimoniales. Por otra parte, las separaciones temporales y juicios inconclusos propendían a crear situaciones de incertidumbre en los miembros de las pare-

75 Arancibia y Dellaferrera, 1980 (Buenos Aires, 1980): 19-20.

76 Arancibia y Dellaferrera, 1980 (Buenos Aires, 1980): 22.

77 Las Siete Partidas del Rey Don Alfonso el Sabio, cotejadas con varios códices antiguos por la Real Academia de la Historia y glosadas por el Lic. Gregorio López (1861) Librería de Rosa y Bouret, París. L. 1, tít. 1, P. 4. constituían un paso previo a la celebración del casamiento, aunque no eran un requisito indispensable para su realización. Los esponsales consistían en una promesa de futuro matrimonio cuya importancia se fundamentaba en la necesidad de una adecuada planificación de alianzas beneficiosas por la familia. Su incumplimiento implicaba incurrir en el pecado delito de perjurio y el damnificado podía demandar ante los tribunales eclesiásticos al ofensor a fin de procurar una reparación material o simbólica por el daño recibido.

78 Conflicto jurisdiccional entre el cura y vicario de Tulumba y el provisor del Obispado en materia de esponsales que eran privativas de éste último. El cura del lugar citaba ante su presencia al demandado en el término de 6 días a responder a la demanda matrimonial y criminal presentada contra él. El provisor da por nulo todo lo actuado; en otro caso el provisor insiste en que el conocimiento de las causas de esponsales corresponde privativamente a esa curia. No hace lugar a la comisión de que el cura de Río Segundo entienda sobre el caso, Cfr. AAC, Juicios por Esponsales, legajo 193, años 1798-1807, t. VI, exp. 6 y 7. 
jas, promoviendo posiblemente la convivencia sin matrimonio y aparejando además, cierta confusión en la definición de los límites aceptables ante comportamientos de crueldad y falta de respeto entre los esposos en los casos de sevicia, pudiendo contribuir a promover, al menos indirectamente, la reproducción de conductas no acordes a la moral católica del matrimonio, a partir de la sensación de impunidad derivada de la falta de resolución de la autoridad eclesiástica en estas cuestiones ${ }^{79}$.

Debe recordarse además la obligación de cumplir con el respeto a los tiempos sagrados que fijaba el calendario eclesiástico en épocas de adviento y cuaresma durante los cuales estaban cerradas las velaciones, ello era causa de la postergación o adelanto de los casamientos en los meses anteriores y posteriores a esas épocas, lo cual podría ocasionalmente, desalentar los enlaces religiosos.

Frente a la defensa de la Iglesia de la indisolubilidad del vínculo matrimonial, autores como Jack Goody han afirmado que como consecuencia de la virtual imposibilidad legal de las parejas para obtener el divorcio, se habría desarrollado en la sociedad una mayor tolerancia a la violencia conyugal y a las infidelidades sexuales ${ }^{80}$.

Teniendo en cuenta que las sentencias y consecuentes castigos aplicados a los autores de las transgresiones a las normas canónicas del matrimonio cumplían, como parece haber sido el propósito de la justicia de la época, una función ejemplificadora en la sociedad, la falta de resolución de tan elevada proporción de causas aparejaría además cierta confusión en la definición de los límites aceptables en estos comportamientos, y promoverían la reproducción de conductas transgresoras y la sensación de impunidad de los maridos golpeadores.

No debe dejar de considerarse por otra parte que no todas las parejas que deseaban formalizar una unión estaban en condiciones de satisfacer los aranceles establecidos a tal efecto. Casarse implicaba un costo material, suponía el cumplimiento de los trámites correspondientes. La satisfacción de los mismos implicaba una interrupción de las actividades de subsistencia. En ese sentido, la necesidad de moderación de los derechos parroquiales considerados muy gravosos fue una cuestión que se planteó desde épocas tempranas, así como la libertad de pagarlos en frutos de la tierra ${ }^{81}$.

79 Sobre la función ejemplificadora de los castigos de la justicia secular en la Córdoba de la primera mitad del siglo XIX puede consultarse: Ghirardi, 1986: 205.

80 Goody, 2001: 85 .

81 Arancibia y Dellaferrera, 1980 (Buenos Aires, 1980): 10-11: los aranceles habían sido reformados en épocas del Obispo Moscoso, sin embargo las nuevas resoluciones no soluciona- 
Como ya se ha visto, los reformadores protestantes habían criticado vivamente la concepción cristiana del matrimonio fundada en la indisolubilidad del vínculo y en la exaltación del ideal de virginidad. Tanto Lutero como Calvino creían que con ello la Iglesia Romana había caído en una contradicción que sólo podía ser salvada a través de la sanción de una legislación muy compleja y prohibitiva en la materia. Entre los aspectos más criticados de la normativa canónica efectuada por los reformistas puede mencionarse la multiplicidad de impedimentos matrimoniales. Efectivamente, los causales de impedimento que inhabilitaban a las personas para unirse en matrimonio eran muy variados y complejos, lo que entendemos, podía contribuir a desalentar los casamientos. Por otra parte, la realidad se complicaba aún más en una sociedad como la que tratamos, donde los lazos de consanguinidad y afinidad constituían una intrincada trama de relaciones en ocasiones difícil de desentrañar para los mismos interesados, fundamentalmente en la campaña en donde la promiscuidad y el hacinamiento en las viviendas tendían a favorecer la sexualidad libre entre sus habitantes ${ }^{82}$.

En los casos de matrimonios secretos, estrechamente asociados a las cuestiones de disenso paterno, la Iglesia consideraba que incurrir en ellos era falta grave, aunque tendió a revalidarlos; sin embargo en algunos casos estableció como requisito para su legitimación períodos de separación temporal; por otra parte, un 33,3\% de los casos permaneció inconcluso, entre ellos un expediente de 402 fojas en el cual, luego de catorce meses de actuaciones el asesor letrado propuso declarar nulo todo lo obrado por considerar que la causa adolecía de defectos de forma sustanciales, sugiriendo ponerla en estado de sumaria ${ }^{83}$. Una vez más, se observan casos de uniones en situación de riesgo, y de familias cuyas circunstancias de conformación adolecían de defectos.

\section{CONCLUSIONES}

Los decretos del Concilio de Trento sobre el matrimonio apenas innovaron cosa alguna respecto a la doctrina tradicional de la Iglesia. Si acaso fueron

ron el problema de lo gravoso de estas cargas para los feligreses, los mismos aumentaron en lugar de reducirse. En 1821, se fijaron nuevos aranceles los cuales no habría establecido costas para la celebración de matrimonios: Ayrolo, 4 (Córdoba, 2001): 39-66, en especial, 42-46. Sobre el tema de los aranceles eclesiásticos durante la época colonial consultar además: Martínez de Sánchez, 25 (Córdoba, 1997): 391-410.

82 Moreno, 16-17 (Buenos Aires, 1997-98): 71.

83 Ghirardi, 2004: 264 y ss. 
toda una declaración de intenciones para hacer frente a las nuevas medidas adoptadas por las iglesias reformadas. Por ello, sobre todo, fijaron dogmáticamente varios presupuestos que establecieron la mayor distancia posible frente a los reformados y que, por esa misma razón, se convirtieron en las señas de identidad de los católicos: el carácter sacramental del matrimonio, su indisolubilidad, el consensualismo, la celebración pública, etc. Al reafirmar que el matrimonio era un sacramento, la Iglesia pudo mantener su monopolio sobre la institución nupcial. Además, lógicamente todas las acciones se encaminaban hacia su defensa; de ahí, los pocos divorcios concedidos, tal y como el caso de la audiencia cordobesa demuestra.

Al mismo tiempo, la defensa del matrimonio significaba la defensa de un modelo de sociedad, modelo que era el mismo que la Monarquía hispánica quería para la América colonial. De ahí que ambas instancias de poder coincidieran y colaboraran: el mantenimiento del orden matrimonial se traducía en el mantenimiento del orden social. No será hasta fines del siglo XVIII cuando los caminos de la Monarquía y de la Iglesia comiencen a separarse. Y en esta defensa los grupos oligárquicos también participarán puesto que pronto comprobaron que el matrimonio y, por extensión, la familia, eran los mejores instrumentos para perpetuarse en sus posiciones dominantes.

Sin haber sido asimilado aún completamente en la práctica en la misma España, el modelo matrimonial tridentino que se pretendía implantar en América como parte del proceso de transmisión cultural y construcción de la nueva sociedad, llegaba a las nuevas tierras también con sus contradicciones y confusiones, generando resistencia, como cabe imaginar. Hubo dudas y no siempre se logró desterrar prácticas que no se consideraban adecuadas: es lo que pasó con los matrimonios clandestinos o con los impedimentos. Por otra parte, costumbres como el amancebamiento, es decir, la convivencia sin matrimonio, de arraigo secular en los comportamientos peninsulares, especialmente en algunas regiones, y practicado por buena parte de los hombres que colonizaron América, no habrían de ser controladas fácilmente y terminarían profundizándose y propagándose, fomentadas por el complejo panorama cultural y socio-étnico que caracterizó a la América española. Promovidas por el rechazo social que generaron los casamientos entre individuos considerados de diferente calidad. Así, el concepto que prescribía la igualdad entre los cónyuges persistió, dificultando por ende el control de las pulsiones de los súbditos y conspirando de hecho contra una práctica universal del matrimonio religioso. Pero, más que nada, lo que hubo fue cierta confusión pues algunas de las directrices emanadas del Concilio no resultaron todo lo clarificadoras que se esperaba. Con todo, Iglesia y Monarquía se afanaron en lograr el mayor cumplimiento posible de las directrices tridentinas y así 
lucharon con denuedo contra las desviaciones, si bien la inmensidad y diversidad territorial y cultural sobre la que intentaban imponerse no dejaría de conspirar contra esos propósitos.

Por otro lado, es más que evidente que el monopolio eclesiástico sobre el matrimonio dio a la institución y a sus ministros un inmenso poder social. El Concilio de Trento pretendía un gran programa de clericalización de la sociedad. El párroco se convertía en la persona clave; no sólo porque él fuera el modelo a imitar sino porque él era quien otorgaba la identidad social. Esto en la América colonial tenía consecuencias innegables: la clase, la raza, podía ser modificada por su voluntad o por su negligencia.

Al final, lo que parece que quedó fue un triunfo del modelo de matrimonio tridentino. Aunque como victoria sólo fuese relativa, muy relativa.

\section{BIBLIOGRAFÍA}

Arancibia, J. M. y Dellaferrera, Nelson, «El Sínodo del Obispo Mercadillo, Córdoba, 1700», Revista Teología, XVI/34 (Buenos Aires, 1980): 137-148.

Ariès, Philippe, El niño y la vida familiar en el Antiguo Régimen, Madrid, Taurus, 1987a.

Ariès, Philippe, «El matrimonio indisoluble», Sexualidades occidentales, Buenos Aires, 1987b.

Arretx, C., Mellafe, R. y Somoza, J., Demografía Histórica en América Latina. Fuentes y Métodos, San José de Costa Rica, Centro Latinoamericano de Demografía, 1983.

Ayrolo, V., «Congrua sustentación de los párrocos cordobeses. Aranceles eclesiásticos en la Córdoba del ochocientos», Cuadernos de Historia, Serie Economía y Sociedad, Centro de Investigaciones Facultad de Filosofía y Humanidades, Universidad Nacional de Córdoba, 4 (Córdoba, 2001): 39-66.

Ayrolo, V., «Cura de Almas. Aproximación al clero secular de la diócesis de Córdoba del Tucumán, en la primera mitad del siglo XIX», Anuario del IEHS de la Universidad Nacional del Centro-Facultad de Ciencias Humanas, 16 (Tandil, 2001): 426-434.

Aznar Gil, Federico R., «Penas y sanciones contra los matrimonios clandestinos en la Península Ibérica durante la Baja Edad Media», Revista de Estudios Histórico-Jurídicos, 25 (Madrid, 2003): 189-214.

Barral, M. E., «Fuera y dentro del confesionario. Los párrocos rurales de Buenos Aires como jueces eclesiásticos a fines del período colonial», Quinto Sol, Revista de Historia Regional, 7 (La Pampa, 2003): 11-33. 
Bonfield, Lloyd, «Avances en la legislación familiar europea», David I. Kertzer y Marzio Barbagli (comps.), Historia de la familia europea, I: La vida familiar a principios de la era moderna (1500-1789), Barcelona, Paidós, 2002: 153-203.

Brundage, James A., La ley, el sexo y la sociedad cristiana en la Europa medieval, México D.F., FCE, 2000.

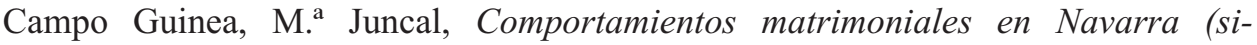
glos XVI-XVII), Pamplona, Diputación foral de Navarra, 1998.

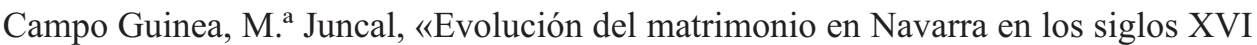
y XVII. El matrimonio clandestino», Ignacio Arellano y Jesús M. ${ }^{a}$ Usunáriz (eds.), El matrimonio en Europa y el mundo hispánico. Siglos XVI y XVII, Madrid, Visor Libros, 2005: 197-210.

Candau Chacón, M. ${ }^{a}$ Luisa, «El matrimonio clandestino en el siglo XVIII: entre el amor, las conveniencias y el discurso tridentino», Estudios de Historia de España, 8 (Buenos Aires, 2006): 175-202.

Carreras, Joan, Las bodas. Sexo, fiesta y derecho, Pamplona, Universidad de Navarra, 2002.

Casey, James, Historia de la familia, Madrid, Espasa Calpe, 1990.

Casey, James, «Familia y tendencias historiográficas en el siglo XX. Introducción general sobre Europa», Francisco Chacón, Antonio Irigoyen, Eni de M. Samara y Teresa T. Lozano (eds.), Sin distancias. Familia y tendencias historiográficas en el siglo XX, Murcia, Universidad de Murcia, 2002: 25-45.

Castañeda, Carmen, Violación, estupro y sexualidad. Nueva Galicia, 1790-1821, Guadalajara, Hexágono, 1989.

Celton, Dora, La Población de Córdoba en 1840, Junta Provincial de Historia de Córdoba, Córdoba, 1982.

Celton, Dora, La población de la provincia de Córdoba a fines del siglo XVIII, Academia Nacional de la Historia, Buenos Aires, 1993.

Celton, Dora, «Selección matrimonial y mestizaje en Córdoba», III Jornadas de Historia de Córdoba, Junta Provincial de Historia de Córdoba (Córdoba, 1997).

Contreras, Jaime, «Procesos culturales hegemónicos: de religión y religiosidad en la España del Antiguo Régimen», Historia Social, 35 (Valencia, 1999): 3-22.

Dedieu, Jean-Pierre, «El modelo sexual: la defensa del matrimonio cristiano», en Bartolomé Bennassar (ed.), Inquisición española: poder político y control social, Barcelona, Crítica, 1984: 231-269.

Del Priore, M. L., «As atitudes em face da mulher no Brasil colonia», M. Luizia Marcilio (ed.), Familia, mulher, sexualidade e Igeja na história do Brasil, São Paulo, Loyola, 1993: 171-189. 
Dellaferrera, Nelson, «El Obispo, único juez en la diócesis», Cuadernos de Historia, 9 (Córdoba, 2000): 137-148.

Di Stefano, R. y Zanatta, L., Historia de la Iglesia en la Argentina. Desde la Conquista hasta fines del siglo XX, Buenos Aires, Grijalbo Mondadori, 2000.

Domínguez Ortiz, Antonio, El Antiguo Régimen: los Reyes Católicos y los Austrias, Madrid, Alianza-Alfaguara, 1973.

Esteinou, Rosario, «El surgimiento de la familia nuclear en México», Revista de Estudios de Historia Novohispana, vol. 31, julio-diciembre (México, 2004) Instituto de Investigaciones Históricas, niversidad Nacional Autónoma de México.

Ferreyra, María del Carmen, «El matrimonio de las castas en Córdoba, 1700-1779», en Junta Provincial de Historia de Córdoba, III Jornadas de Historia de Córdoba, (Córdoba, 1997): 285-321.

Flandrin, Jean-Louis, Orígenes de la Familia Moderna, Barcelona, Crítica, 1979.

Flores, A. y Chocano, M., «Las cargas del Sacramento», Revista Andina, II (Cuzco, 1984): 427-463.

Gaudemet, Jean, El matrimonio en Occidente, Madrid, Taurus, 1993.

Ghirardi, Mónica, La campaña cordobesa a través de los procesos judiciales, Córdoba, Tapas, 1986.

Ghirardi, Mónica, «Historias íntimas de hombres y mujeres en el orden finicolonial cordobés», Colonial Latin American Historical Review, XII/4 (New Mexico, 2003): 373-414.

Ghirardi, Mónica, Matrimonios y familias en Córdoba, 1700-1850. Prácticas y representaciones, Córdoba, Centro de Estudios Avanzados, Universidad Nacional de Córdoba, 2004.

Ghirardi, Mónica (comp.), Cuestiones de familia a través de las fuentes, Córdoba, Centro de Estudios Avanzados, Universidad Nacional de Córdoba, 2005.

Gonzalbo Aizpuru, Pilar, Familia y orden colonial, México, El Colegio de México, 1998.

Gonzalbo Aizpuru, Pilar, «Las mujeres novohispanas y las contradicciones de una sociedad patriarcal», Pilar Gonzalbo Aizpuru y Berta Ares Queija (coords.), Las mujeres en la construcción de las sociedades iberoamericanas, Sevilla-México, 2004: 121-140.

Gonzalbo Aizpuru, Pilar, «La familia novohispana y la ruptura de los modelos», Colonial Latin American Review, IX (New Mexico, 2000): 7-19.

Goody, Jack, La familia europea, Barcelona, Crítica, 2001.

Goody, Jack, La evolución de la familia y el matrimonio en Europa, Barcelona, Herder, 1995. 
Icaza Dufour, México, 1987.

Jedin, Hubert, Historia del Concilio de Trento, IV-2: Tercer periodo de sesiones y conclusión. Superación de la crisis gracias a Morone. Conclusión y ratificación, Pamplona, Universidad de Navarra, 1981.

Jedin, Hubert, Historia del Concilio de Trento, III: La etapa de Bolonia (1547-1548). Segundo periodo de Trento (1551-1552), Pamplona, Universidad de Navarra, 1975.

Kamen, Henry, Cambio cultural en la sociedad del Siglo de Oro. Cataluña y Castilla, siglos XVI-XVII, Madrid, Siglo XXI, 1998.

Latasa, Pilar, «La celebración del matrimonio en el virreinato peruano: disposiciones sinodales en las archidiócesis de Charcas y Lima (1570-1613)», Ignacio Arellano y Jesús M. ${ }^{a}$ Usunáriz (eds.), El matrimonio en Europa y el mundo hispánico. Siglos XVI y XVII, Madrid, Visor Libros, 2005: 237-256.

Lavallé, Bernard, «Divorcio y nulidad de matrimonio en Lima (1650-1700)» (La desavenencia conyugal como indicador social), Revista Andina, IV/2 (Cuzco, 1986): 427-482.

Lavrin, Asunción (coord.), Sexualidad y matrimonio en la América hispánica, siglos XVI-XVIII, México D.F., Consejo Nacional para la Cultura y las Artes-Grijalbo, 1991.

Le Goff, Jacques, El nacimiento del purgatorio, Barcelona, Gedisa, 1981.

Mallo, Silvia, "Justicia, divorcio, alimentos y malos tratos en el Río de la Plata, 1766-1857», Investigaciones y Ensayos, 42 (Buenos Aires, 1992): 373-400.

Martínez de Sánchez, Ana M.a , «El arancel eclesiástico en el Obispado del Tucumán», en Revista de Historia del Derecho, 25 (Córdoba, 1997): 391-410.

Montero Gutiérrez, Eloy, El matrimonio y las causas matrimoniales, Madrid, Imprenta Sáez, 1945.

Moreno, José Luis, «Sexo, matrimonio y familia: la ilegitimidad en la frontera pampeana del Río de la Plata. 1780-1850», Boletín del Instituto de Historia Argentina y Americana «Dr. Emilio Ravignani», 16-17 (Buenos Aires, 1997-98): 61-82.

Ortega Noriega, Sergio, «Discurso teológico de la Iglesia católica», Annie Molinié Bertrand y Pablo Rodríguez Jiménez (eds.), A través del tiempo. Diccionario de fuentes para la historia de la familia, Murcia, Universidad de Murcia, 2000: 73-76.

Rincón, Tomás, El matrimonio, misterio y signo. Siglos IX-XIII, Pamplona, Universidad de Navarra, 1971.

Rodríguez Jiménez, Pablo, Seducción, amancebamiento y abandono en la Colonia, Bogotá, Fundación Simón y Lola Guberek, 1991. 
Rodríguez Sánchez, Ángel, La familia en la Edad moderna, Madrid, Arco Libros, 1996.

Salinas Álvarez, C., Las chilenas de la colonia: virtud sumisa, amor rebelde, Santiago de Chile, LOM, 1994.

Seed, Patricia, Amar, honrar y obedecer en el México colonial. Conflictos en torno a la elección matrimonial, 1574-1821, México D.F., Consejo Nacional para la Cultura y las Artes-Grijalbo, 1991.

Socolow, Susan, «Parejas bien constituidas: la elección matrimonial en la Argentina colonial, 1778-1810» en Anuario del Instituto de Estudios Históricos y Sociales de Tandil, V (Tandil, 1990).

Socolow, Susan, Los mercaderes del Buenos Aires virreinal: familia y comercio, Buenos Aires, Ediciones la Flor, 1991.

Tejero, Eloy, El matrimonio, misterio y signo. Siglos XIV-XVI, Pamplona, Universidad de Navarra 1971.

Watt, Jeffrey R., «El impacto de la Reforma y la Contrarreforma», David I. Kertzer y Marzio Barbagli (comps.), Historia de la familia europea, I: La vida familiar a principios de la era moderna (1500-1789), Barcelona, Paidós, 2002: 205-245.

Fecha de recepción: 17-3-2007

Fecha de aceptación: 10-10-2007

\section{MARRIAGE, THE COUNCIL OF TRENTO AND SPANISH AMERICAN}

This papper pretends to investigate about Council of Trento marriage's rules and the problematics around the matrimonial institution in Hispanic America. It pretends to evaluate the observance degree and applicantion of the Council's dispositions, and reflectionate about succes, or failure, of the social organization's program established by the hispanic Monarchy and the Catholic Church, in which marriage was a very significant piece. Unpublished source files about Causes of separation, nullity and unfulfilled matrimonial promises corresponding to the diocesan court of Córdoba, today's Argentina's territory, period 1688-1850, proportionate elements of reflection and analysis.

KEY WORDS: Trento's Council, marriage, divorce, family, social history, Córdoba-Argentina. 